Revue des patrimoines

$1 \mid 2001$

Mélanges en mémoire de Joël Perrin

\title{
Joël au quotidien
}

Jean-Claude Lasserre

\section{OpenEdition}

Journals

Édition électronique

URL : http://journals.openedition.org/insitu/1044

DOI : 10.4000/insitu.1044

ISSN : 1630-7305

\section{Éditeur}

Ministère de la culture

\section{Référence électronique}

Jean-Claude Lasserre, « Joël au quotidien », In Situ [En ligne], 1 | 2001, mis en ligne le 24 janvier 2012, consulté le 20 avril 2019. URL : http://journals.openedition.org/insitu/1044 ; DOI : 10.4000/insitu.1044

Ce document a été généré automatiquement le 20 avril 2019

\section{(2) $\odot \Theta \Theta$}

In Situ Revues des patrimoines est mis à disposition selon les termes de la licence Creative Commons Attribution - Pas d'Utilisation Commerciale - Pas de Modification 4.0 International. 


\title{
Joël au quotidien
}

\author{
Jean-Claude Lasserre
}

Figure 1

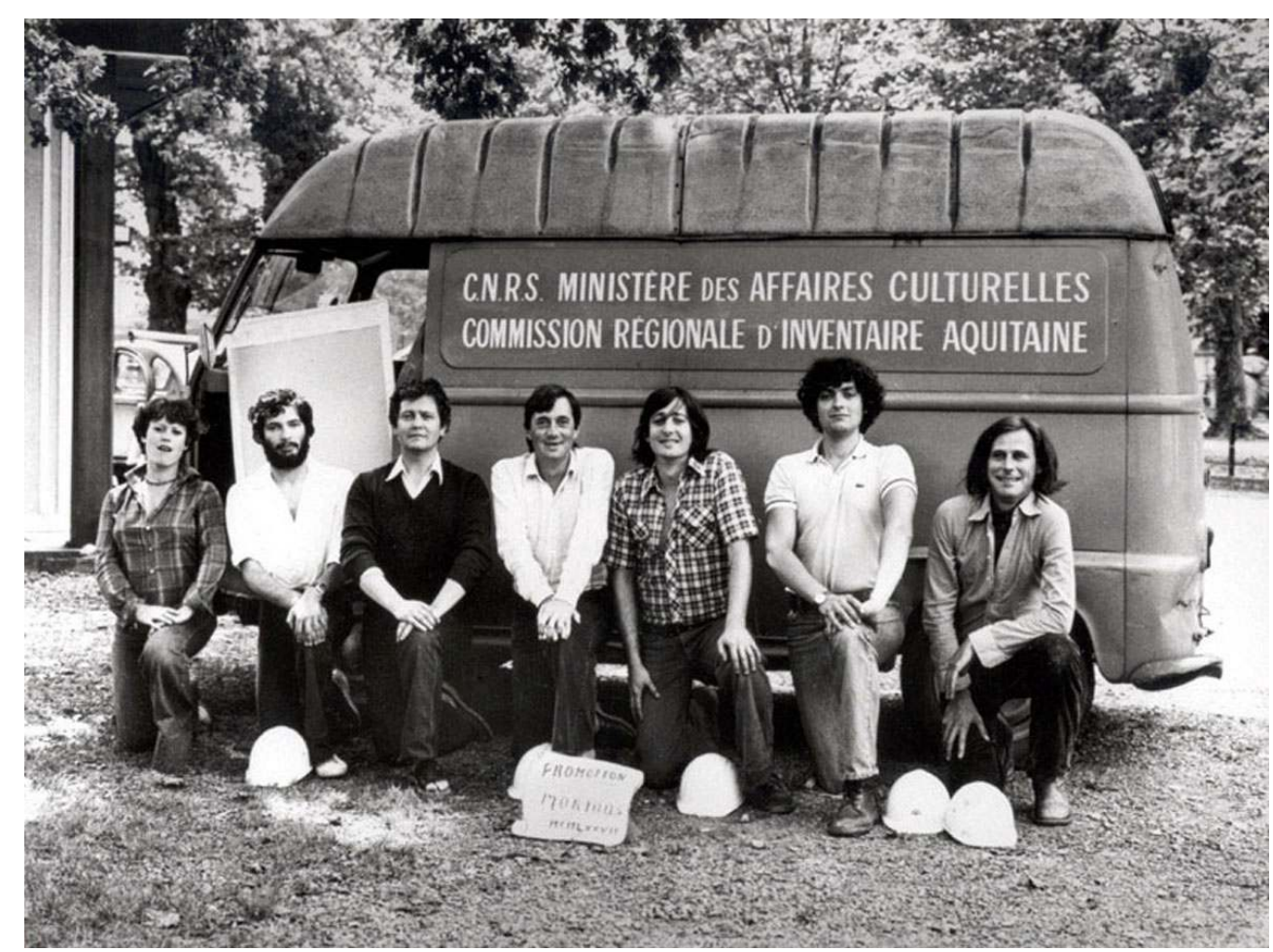

Morlàas, promotion 1977, Phot. Inv. B. Chabot

(C) Inventaire général, ADAGP, 1977

«La spécialité de Philippe [...] était, sous prétexte d'étudier les fermes, de repérer les belles armoires ornées de croix de Malte ou de Morlàas, où il soupçonnait les grandsmères du Vic-Bilh [...] de cacher un trésor démembré à la Révolution. L'armoire repérée, il s'agissait de se la faire ouvrir [...] Il passait alors à Joël dont l'extrême courtoisie glissait 
sur les toiles cirées des tables de ferme avec une légèreté de poudre de riz, entre les pattes jaunes et crispées du poulet récemment plumé [...] le dictionnaire des poinçons d'argent et le compte-fil qui, systématiquement oublié, fournirait un prétexte de retour dans le cas où la première tentative de forçage de l'armoire se serait avérée infructueuse. Le plus souvent, la serrure tournait après quelques minutes d'entretien : tout occupée à exposer à Joël les arcanes du mariage champêtre (occasion de l'arrivée de l'armoire dans la maison en 1763), la propriétaire ne prêtait plus attention à Cathy qui en profitait pour exhumer des assiettes de Samadet ourlées de cobalt et serties de manganèse et des toupins de Garos aux panses ventrues et à la patine digne d'un bronze de Ghiberti ».

2 Ces quelques lignes empruntées à une fable amusée de notre collègue Philippe Araguas dans la revue d'art Le Festin - numéro consacré à l'Inventaire général d'Aquitaine esquissent, entre humour et tendresse, un portrait de Joël Perrin, au quotidien, de l'homme, du collègue et du chercheur, en ces années heureuses et formatrices des campagnes d'inventaire dans le Vic-Bihl. C'était juste avant son départ pour Paris et le bureau de la méthodologie, après un long service de presque 20 ans à Bordeaux, à l'Inventaire d'Aquitaine. Cette Aquitaine où il était né et s'était marié, qu'il connaissait jusqu'aux moindres recoins d'armoires de sacristie, qu'il aimait et qu'il se plaisait à retrouver, sujet d'étude - il était le spécialiste incontesté du château de Cadillac près Bordeaux - et objet de plaisir - le panorama des Pyrénées depuis Lalongue ; l'eau, le soleil et le ciel si changeant de Petit Piquey, auxquels chaque année il restait fidèle -

Il jouissait parmi nous d'un statut particulier dû certes à ses grandes compétences scientifiques qui firent de lui un spécialiste incontesté dans les domaines de la sculpture, des objets et du mobilier civil et religieux, mais surtout à ses qualités humaines qui le rendaient particulièrement attachant : extrêmement courtois et attentif aux autres, avec cette politesse du cœur que tout naturellement il pratiquait, avec sincérité et discrétion. Il était généreux de lui-même et de ses talents jusqu'à la prodigalité. La passion qui l'animait, souvent au mépris de sa santé, faisant de lui un travailleur impénitent et exigeant, voire tatillon, à la curiosité perpétuellement en éveil, le conduisait à certains comportements dont le souvenir nous enchante et nous attendrit à chaque évocation, comme ce fameux soir - il nous raconta la scène le lendemain de sa manière mi-sérieuse mi-amusée - où resté seul à travailler dans l'hôtel magnifiquement délabré que le service occupait alors rue de Grassi à Bordeaux, il fut au bout d'un certain temps - il était là depuis le matin et la nuit était tombée - tenaillé par une petite faim qu'il voulut satisfaire. Quel ne fut pas son étonnement de trouver cafés et restaurants fermés, étonnement qui ne prit fin que lorsque rentré chez lui, il se rendit enfin compte qu'il était trois heures du matin. Ça, c'était aussi Joël, le Joël proche que nous aimions et taquinions à souhait, avec ce chapelet d'histoires et de souvenirs qu'à chaque rencontre et à la moindre occasion nous prenions plaisir à égrener à satiété.

Ces 20 années passées au quotidien avec Joël, dans une période où l'avidité du savoir et des découvertes le disputait aux utopies des premières années de l'Inventaire, où l'affection qui nous unissait tous, en dépit d'homériques disputes et de perturbantes crises, permettait « de surmonter toutes les métamorphoses, celles des individus et celles des institutions ", ces années-là comptent parmi les plus lumineuses de notre vie, elles éclairent notre chagrin infini et notre désarroi, elles nous éclaireront toujours. 


\section{ANNEXES}

\section{Notices existantes dans les bases de données nationales :}

Notices de la base Mérimée :

- Canton de Cadillac

- Canton de Peyrehorade

- Cantons de Garlin, Lembeye, Montaner, Morlàas, Thèze

Notices de la base Palissy(Lot-et-Garonne)

INDEX

Mots-clés : inventaire général, en ligne, journal, revue électronique, revue numérique, périodique, patrimoine, histoire de l'art, France

Keywords : on line, electronic journal, ejournal, heritage, history of art

\section{AUTEUR}

JEAN-CLAUDE LASSERRE

Conservateur régional de l'Inventaire, DRAC Aquitaine 54, rue Magendie 33074 Bordeaux Cedex. jean-claude.lasserre@culture.gouv.fr 